See discussions, stats, and author profiles for this publication at: https://www.researchgate.net/publication/286454531

\title{
Sobre loas y festines o el elogio a las virreinas en la Nueva España durante la época de Carlos II
}

Chapter · January 2007

DOI: 10.13140/RG.2.1.1369.4806

\section{CITATIONS}

2

1 author:

as

Judith Farré

Spanish National Research Council

32 PUBLICATIONS 20 CITATIONS

SEE PROFILE
READS

15

Some of the authors of this publication are also working on these related projects:

Project From the Edges of the Archive, II: Ephemeral Writing in the Viceroyalties of the Indies (ELBA) View project 


\title{
SOBRE LOAS Y FESTINES \\ O EL ELOGIO A LAS VIRREINAS EN LA NUEVA ESPAÑA DURANTE LA ÉPOCA DE CARLOS II ${ }^{1}$
}

\author{
Judith Farré Vidal \\ Tecnológico de Monterrey
}

Resulta necesario iniciar estas reflexiones acerca del tratamiento panegírico a las virreinas novohispanas durante la segunda mitad del siglo XVII tomando como punto de partida la configuración simbólica de la imagen de la reina marcada desde la metrópoli. De entrada, cabe decir que son escasos los textos teóricos publicados en España para fijar el arquetipo ideal de reina, modelo de virtudes para las soberanas ${ }^{2}$. Es por ello que los principios ideológicos sobre los que se configura el referente simbólico para su elogio proceden de las manifestaciones artísticas emanadas de la corte como retratos oficiales, monumentos efímeros, emblemas y jeroglíficos, etc. Y dentro de este último campo surge una de sus imágenes más representativas: la metáfora lunar. La

${ }^{1}$ Este trabajo forma parte de una investigación más amplia que se enmarca en el proyecto "La imagen del poder en la corte virreinal (1665-1700)", subvencionado con una beca de investigación otorgada por CONACYT en la Convocatoria de Investigación Básica 2004. Número de referencia: 47731.

2 Una de las pocas excepciones es el opúsculo de J. Micheli y Márquez, El cristal mas pvro representando imagines de Diuina, y Humana politica, para exemplo de Principes, labrado en las acciones heroicas de Doña lsabel de Borbon, Reyna de España, de feliz memoria (Zaragoza, 1644): «Su peculiaridad consiste en que este espejo de principes toma como modelo a una reina consorte, que ni siquiera llegó a ser regente. Es, tal vez, el único libro político del siglo xvrr español que describe a la reina ideal, modelo de futuras soberanas.» (Minguez, 1993, p.32, n6). 
equiparación entre Reina y Luna completa así la metáfora solar del Rey, pues la Luna se nutre de la luz solar durante la noche. Además, se trata de los dos astros de mayor tamaño, que pueden ejercer una especie de matrimonio que preside, de día y de noche, todo el paisaje celeste. Aunque esta dualidad no se establece en términos de igualdad, frente a la preponderancia simbólica del Sol quedan claros los valores que se elogian en las reinas lunares como baluartes para garantizar la estabilidad política: por su fecundidad al asegurar la sucesión dinástica y por poder desempeñarse como regentes en la ausencia nocturna del Rey Sol.

Otra de las metáforas celestes y relacionadas con la luz que puede asociarse a las reinas es la de la Aurora que, como personaje alegórico e inicio del día, remite simbólicamente a los valores de fertilidad que forman parte de la retórica áulica para su encomio. Al carácter cíclico de cada amanecer, entendido como alegoría de continuidad dinástica, debe añadírsele toda la tradición clásica del amanecer mitológico, lo que permite, además, un elogio a la belleza de la reina. Según la Iconología de Ripa, la Aurora aparece caracterizada como

Jovencita alada, para indicar la rapidez de su movimiento, pues muy pronto desaparece. Es de encarnada tez y viene revestida de amarillo manto, llevando en el brazo izquierdo un cestillo repleto de variadas flores, mientras con la misma mano sostiene una candela encendida. $\mathrm{Va}$ esparciendo flores con la diestra ${ }^{3}$.

A partir de estas premisas y por lo que respecta a la posición simbólica que desempeñan las esposas de los representantes directos de la Corona en la Nueva España, cabe decir que a grandes rasgos el protocolo áulico fija los mismos parabienes que se estipulan para el virrey; aunque, como veremos, la vida cotidiana en el espacio de la corte novohispana se encargará de fijar su especial perfil como consorte del

${ }^{3}$ Ripa, Iconología, vol.I, p. 120. López Torrijos analiza la representación de la Aurora de Carducho en uno de los techos del palacio de El Pardo, a principios del siglo xvir: "como figura alada, en pie sobre su carro esparciendo flores» (López Torrijos, 1985 , p. 353). Otro dibujo de la segunda mitad del siglo xvir, realizado por un artista próximo a Coello, «representa la imagen de Aurora arrojando flores» (López Torrijos, 1985, p. 354). En la interrelación entre pintura y poesía, Ruiz Lagos señala cómo se consolida el atributo básico de las flores en el diseño calderoniano para la Aurora, que sale "con un manto azul y corona de flores». (Ruiz Lagos, 1967, p. 58) gobernante $y$, por tanto, también sus atributos simbólicos quedarán bien delimitados. Si bien desde la época de Carlos V la corte española se regía por el ceremonial de los grandes duques de Borgoña, basado en el ocultamiento de la persona del monarca para salvaguardar la dignidad y el respeto de sus súbditos, en la corte virreinal el protocolo dictaba justamente lo contrario, puesto que

Para encarnar la autoridad de un rey invisible y lejano como el de España era necesario, paradójicamente, un virrey muy visible, con la suficiente jerarquía y dignidad para autorizar sus actos de gobierno e imponer la obediencia a la orgullosa oligarquía criolla. Para ello, además de designar al cargo a miembros de la alta nobleza castellana, se concedió los virreyes el uso de distintos símbolos de la potestad real, como el ser recibidos bajo palio procesional en su entrada triunfal a la capital, el derecho a usar un tiro de seis caballos en el carruaje y el goce de una escolta personal armada y uniformada, la famosa guardia de alabarderos ${ }^{4}$.

Esta visibilidad con la que se contempla la figura del virrey en los ceremoniales públicos de ostentación de la autoridad no aplica de la misma manera para su consorte. Diego García Pares (1730-1811), que en 1755 pasó a la Nueva España como alférez de artillería y parte del séquito del virrey marqués de las Amarillas, repasa minuciosamente en su Diario particular del camino que sigue un virrey en México las vicisitudes protocolarias que impone la presencia de una virreina en toda la etiqueta de recibimiento al nuevo gobernante. En el autógrafo del Diario aparecen constantes precisiones a partir de las fórmulas « $\mathrm{Y}$ si va Virreina» o "En caso de que el nuevo Virrey lleve esposa» o "Cuando ha ido Virreina", etc. Esas distinciones pueden resumirse bajo dos rubros. El primero afecta a las cuestiones eminentemente prácticas de desplazamiento que supone el viaje desde Veracruz hasta la Ciudad de México y que implican la distribución de todo el cortejo en literas. Por ejemplo, ya desde Veracruz se impone una premisa básica para todo el tránsito en carretera:

disponen despachar por delante no sólo el grueso del equipaje, si[no] también lo más de la familia, quedándose únicamente los precisos sujetos que deben seguir a Su Excelencia, como son el Secretario que traiga de su confianza (que todos lo traen aunque haya del virreinato)

${ }^{4}$ Escamilla González, 2005, pp. 378-379. 
el Caballerizo, Mayordomo, un Ayuda de Cámara, un Cocinero, un Repostero y algún otro sirviente de esta clase. Esto es viniendo solo el Virrey, pero si hay Virreina son necesarios en su inmediación lo meno dos pajes de cuatro o seis que debe tener un Virrey de México, las criadas, dos lacayos y algunos otros sirvientes que necesite la Virreina. Pero siempre es muy conveniente que el grueso de la familia se despache por delante, encontrando ésta en todos los tránsitos el obsequio y asistencia correspondiente. [...]

A Veracruz baja el Caballerizo o persona allegada del Obispo de Puebla de los Ángeles a cumplimentar al nuevo Virrey, llevando una hermosa litera para Su Excelencia [...]. Si va Virreina es lo corriente que ocupe en el recorrido la litera del Obispo de la Puebla, y para el Virrey se hace traer otra del pueblo de Jalapa, como las que se necesite para las criadas y allegádos de distinción del Virrey [...]. Advirtiéndose que la marcha en litera la hace solo el Virrey en la suya, y lo mismo la Virreina, para ir con más comodidad y desahogo ${ }^{5}$.

El siguiente apartado de distinciones afecta a la etiqueta y al protagonismo simbólico del virrey como nuevo gobernante y representante directo de la monarquía hispana. Puede verse en los fragmentos de narración que se ocupan de la llegada a las ciudades en las que el virrey hace entrada pública a caballo, como ocurre al desembarcar en Veracruz, Tlaxcala, la Puebla de los Ángeles, Otumba, Chapultepec y México. En este caso, el protocolo impone que la virreina se adelante para conceder todo el protagonismo al virrey y espere, juntó al resto de las nobles locales, la entrada pública de su esposo. Sirva de ejemplo la entrada en Tlaxcala, la segunda que aparece descrita' en el Diario de García Pares, tras haber tratado el desembarco en Veracruz:

[sobre Alahuazán] mísero y muy corto, pero memorable porque en él fue donde el invicto Capitán Hernán Cortés firmó las paces con la valerosa nación tlaxcalteca. Por eso ha sido la ciudad de Tlaxcala la primera en donde los virreyes hicieron sus entradas públicas a caballo, y como este ceremonial se ha hecho siempre con la mayor pompa y lucimiento, era preciso que a las once del día llegase el Virrey a la inmediación de Tlaxcala, donde dejaba los coches para montar a caballo. Cuando ha ido Virreina, ésta sigue sin detenerse a apearse en el palacio o casas capitu-

\footnotetext{
5 García Pares, 1994, pp. 78-80
}

lares de la ciudad, para ver desde sus balcones la lucida entrada pública del Virrey ${ }^{6}$.

Esta última apreciación nos sitúa ya en el espacio de visibilidad de la virreina y resulta útil para extraer algunas conclusiones sobre el espacio público que se asigna a la esposa del virrey en la vida novohispana. De su presencia notable da cuenta la preocupación de la etiqueta por asignarle un lugar preponderante que, aunque secundario, no eclipse la preeminencia de su esposo como mandatario político. Como consorte, su protagonismo simbólico en el exclusivo momento de las entradas a caballo del virrey en cada ciudad se relega al segundo plano del balcón, pues los privilegios que ostenta el virrey en la toma de posesión proceden directamente de la Corona.

Una vez instalados en la corte novohispana, el papel desempañado por la virreina seguirá las mismas directrices, puesto que tampoco existe una reflexión teórica acerca de las funciones ideales de una virreina. A pesar de ello, puede establecerse que existe una constante preocupación protocolaria por enmarcar la presencia social de la virreina en una especie de segundo espacio, más discreto y con mucha menos proyección de visibilidad que la de su esposo. En este sentido, la arquitectura de los edificios oficiales adquiere el

'El Diario resume a continuación la entrada pública en la ciudad y el recibimiento con arco triunfal y loa:

Con este orden y aclamaciones del pueblo llegaba el Virrey hasta la esquina de la plaza principal y del palacio, donde estaba erguida una hermosa perspectiva de arco triunfal, pintadas en jeroglíficos las acciones ilustres del nuevo Virrey, figurando las puertas cerradas mientras que desde un tablado hace el elogio en verso un sujeto instruido en ello, que concluida la arenga abren las puertas, entrando por ellas el Virrey con comitiva y aclamaciones, que sigue así hasta el atrio de la iglesia mayor, donde después de hacer oración al modo que se dijo en Veracruz [es decir: "Entrando en la iglesia, besa la cruz que le presenta el Preste y toma el agua bendita de su mano, siguiendo al presbiterio al lado del Evangelio, donde le tienen puesto sitial e insignias de Vicepatrono, y hace oración mientras el coro canta el Te Deum o salve con más o menos ostentación, según las iglesias. Y esto es en todas", pp. 74-75], pasa a descansar a su morada del palacio o casas capitulares, donde permanece tres días después, esmerándose en obsequios los indios con muchos castillos de fuego y fiestas de toros. En uno de estos tres días suben a visitar el portentoso santuario de María Santísima de Ocotlán, que con justo motivo veneran allí sus moradores por Patrona, y aunque la iglesia está sobre un cerro, se sube en coche hasta ella” (García Pares, 1994, pp. 96-99). 
valor de referencia para esta metáfora del ocultamiento femenino, irreinan del real Palacio de México, una ucelosía de madera dorada y ensamblada detrás de cuyos cristales la esposa del gobernante y sus damas podían contemplar la plaza Mayor sin ser vistas ${ }^{7}$ y la tribuna cerrada que se colocaba en la Catedral, detrás del estrado y al lado de la banca para los criados mayores del virrey, para que la virreina pudiera seguir los servicios religiosos oculta de las miradas del pueblo ${ }^{8}$. A la vista de todo ello, podría decirse que social y, por lo tanto simbólicamente, la virreina ejerce su posición pública desde una especie de ocultamiento visible. Ello resulta de nuevo patente al constatar una de las pocas actividades que oficialmente ella podía llevar a cabo de manera individualizada: las visitas a los conventos de clausura «como participantes de lo que pertenece a sus maridos por la representación que hacen de la persona de Su Majestad»?

Las entradas en la clausura ${ }^{10}$ se convirtieron en el pretexto para organizar distintos saraos en homenaje a los virreyes y, en especial, a

7 Escamilla González, 2005, p. 387.

* Escamilla González, 2005, p. 390.

"Escamilla González, 2005, p. 391.

16) Romero de Terreros reproduce algunas de las anécdotas más sobresalientes de eccándalo que protagonizó la marquesa de Villamanrique, esposa de Álvaro Manrique de Zúñiga (1585-1590), que

se destacó por noticias poco edificantes. Por la Relación de la Visita que hizo fay Alonso Ponce, comisario general de la Orden Seráfica a los Provinciales de Nueva España se sabe que la virreina era de carácter dominante y de conducta livera. En 1586 los virreyes se hospedaron ocho días en el convento franciscano ligera. En 1586 los de San Bernardino trasiadandose con todo su ajur hos indos a saber que los virreyes visitaban el pueblo realizaron flestas en su honor en las que, por cierto, murieron tres de ellos por un tiro perdido. A las fiestas asistían los religiosos y murieron tral de la orden, fray Pedro de San Sebastián. Se dijo que la disciplina de provincial de la orden, fray Pedro de San Sebastán. Se dió que la disciplina cú convento se relajó enormemente. El escándalo se extendió cuando se rompió la clausura conventual con la presencia no sólo de la virreina sino de las damas y las criadas que la acompañaban y que se paseaban por las celdas de los frailes. El las criada que la ánica fue que un fraile lego nadó en un estanque en presencia colmo, según la crónica, fue que un fraile lego nadó en un estance terreros, 1944, p. 18).

Men sase de los virreMantel Ramos afrita que sen yes", aunque relacionadas con sts visitas a las clauras, sobresalen algunas noticias recogidas en las crónicas y diarios de la época. Es el caso de Leonor de Portug recogidas en las crón (1624-1635), «quien asistía cotidianamente a la madre Inés de las virreinas. EI festín que en 1680 dedicó el convento de Santa Clara en México para recibir a la nueva virreina, la condesa de Paredes, es un claro ejemplo de ello, ya que se trata de una ceremonia de bienvenida, paralela a la que públicamente antes se había dedicado al nuevo virrey, aunque esta vez desde la privacidad encubierta del espacio cerrado del convento. El impreso en cuestión ${ }^{11}$ inicia con los preliminares habituales del género: una dedicatoria a la virreina y varias piezas laudatorias que recuerdan la entrada en la ciudad de los nuevos virreyes, con alusiones al Neptuno alegórico, arco diseñado por Sor Juana para la ocasión, y distintos juegos retóricos a propósito de las dilogías surgidas entre la claridad de la luz de la belleza de la virreina y la orden del convento de Santa Clara que le dedica el festejo.

En la «Dedicatoria» de Joseph de la Barrera, así como en el resto de indicaciones escenográficas, emblemas y glosas a los elogios, abundan el tono hiperbólico y las citas en latín procedentes de Ovidio. Tras las habituales fórmulas de captación de benevolencia, dicho preámbulo cierra con una apelación dirigida a justificar la entrega a la imprenta del festejo:

No por eso dejara la mía de ofrecer a las plantas [de V.] Exa. este festivo obsequio, con que el convento de [Reli] giosas de S. Clara, a esmero de sus generosos afectos se desempeñó amante, logrando por suyo el festejo lo que pudiera haber desmerecido por mío que ser muy del agrado de V. Exa. Y aunque fue religioso por la parte en que se hizo y novicio, por ser el primero que saco a luz, no me parece le tendrán a mal el que salga de la clausura [para que] solicite su aprobación y logre la dicha que espera [su] [b]enigna aceptación de $\mathrm{V}$. Exa., a quien prospere Dios muchos años con las felicidades que desea. (Festin, A2v)

la Cruz, fundadora del convento de San José de carmelitas descalzas y quien ayudó a la monja en el momento de su muerte. Esto fue mal visto por el axzobispo Pérez de la Serna quien celoso de su autoridad prohibió la asistencia constante de la virreina a los monasterios femeninos». Asimismo, la esposa del virrey conde de Galve, doña María Elvira de Toledo, fue muy devota de la Virgen de los Remedios, en cuyo santurio permanecía largas temporadas. Gracias a una de estas estancias, no estuvo presente en la rebelión popular de 1692 , durante la cual se incendiaron el palacio y el edificio del ayuntamiento (Ramos, 1996, pp. 39-41).

1 Jan noticia del impreso Medina, 1907, vol. II, p. 528; Beristain, Biblioteca hispanoamericana septentrional, vol. I, p. 153 y Andrade, Ensayo bibliográfico mexicano del siglo $X$ VII, n. 754, por referencia a Beristain. La referencia completa aparece en la bibliografía final y en adelante citamos habiendo modernizado la ortografía y sintaxis, con el nombre de Festín e indicando entre paréntesis el número de folio. 
La aceptación que se espera de la condesa de Paredes para publicar el impreso apunta a lo que comentábamos en líneas anteriores acerca del manifiesto ocultamiento del encomio a la virreina, pues la clausura religiosa del convento sobre la que se ampara el festín pasaría a tener una proyección pública excepcional a través de su divulgación impresa, de ahí el sentido de esta súplica final. El ruego también insiste en el carácter religioso del festejo, quizá sólo por celebrarse en la clausura, ya que la acotación que sigue a esta dedicatoria da el detalle de la aparición de "doce niñas del mismo convento» (Festín, A4r) que con un baile darán inicio a la fiesta, descritas de la siguiente manera:

Ésta [«danza primorosa a todas luces y con mil primores lucida»] [la] compusieron doce niñas del mismo Convento, mejor dijera animados Abriles, que con la pompa de sus floridos adornos pudieron ser emulación de Flora o peregrina copia de Amaltea; en ellas a un tiempo se vieron bien hermanadas la destreza en el esmero de su baile con la pompa en la curiosidad de su aliño. Para aquél sirvió la aplicación, para éste se aplicaron vistosos atavíos de lucidas galas y ricas joyas y galantes plumas de que todas salieron adornadas, pudiendo con ellas cada una ser gallardo pavón de la que celebraba Juno. (Festín, A4r)

El cuadro inicial del baile de antesala al Festín se completa con las ocho coplas que canta la Música y que sirven para connotar el bucolismo dramático de la pieza como marco retórico y temático del elogio, al mismo tiempo que como preludio de los dos ejes sobre los que se trazarán posteriormente los argumentos de Tetis y Flora:

Gallardas zagalejas

de aquestos verdes prados,

afrenta del Abril

emulación del Mayo,

salid, salid gozosas

a ver en vuestros campos

una beldad que asiste,

un sol que hoy ha rallado.

Veréis que en sus primores

Cupido está admirando

de Flora la hermosura,

de Venus el retrato.

\author{
Veréis que los arroyos \\ de verla van helados \\ y en dulces escarceos \\ espejos le hacen claros. \\ Sacad, serranas bellas, \\ en tan festivo aplauso \\ el traje a lo cortés, \\ el baile a lo villano. \\ Cortad de los jardines \\ mil olorosos nardos, \\ claveles y azucenas, \\ tomillos y mastranzos. \\ Haced guirnaldas de ellos \\ porque el matiz gallardo \\ tocado se ha de flores \\ ¡Oh, flor de los tocados, \\ tocad las castañetas \\ y en baile concertado, \\ al son de gaitas dulces, \\ resuene todo el campo! (Festín, A4r)
}

Sigue a continuación la pieza dramática anunciada bajo el nombre de Festín y que reproduce el esquema genérico característico de las loa de fiestas reales y casas particulares. La hipótesis de que en realidad se trata de una loa a la que podía seguir la representación de una comedia de la que no hay ninguna noticia en los preliminares ${ }^{12}$, parece reforzarse en la açotación que describe el espacio de la representación:

Ya aguardaba la Loa en un hermosísimo ostentativo teatro, en que parece hecho el resto la curiosidad y logró su desempeño el adorno quedó pues todo el Auditorio en un recatado, grave silencio, tal que dél se pudo decir lo que de otro semejante el Poeta: Conticuere omnes, intentique ora tenebant (Virgil. Eneid.). A este tiempo cantó la Música (este nombre merece por antonomasia la que a todas voces es esmóny témora de la esteneza y rémora de la atención, de cuya suavidad comparada con la que de Orfeo celebró la antigüedad fabulosa ficción) [...] Es la Madre Juana Teresa de

${ }^{12}$ Además de que el título del impreso habla de un Festín, cuando el relator describe los preliminares de la representación y la puesta en escena de la loa relator este tipo de festejos precedía siempre a una conediasta en escena de la loa que, en la relación a imprenta, condensaban el elogio a la nueva virreina de quien se pretendía obtener el pues ésto 
San Antonio a cuyo elogio sólo me mueve un sencillo conocimiento de la verdad en que no me parece seré censurado, aun de la más viva emulación, pues en esto sólo digo la aclamación de todos a una voz que cada día da nuevo asunto para alabar al soberano Autor. Digo, pues, que la Música dando principio a la Loa cantó esta Letra: (Festín, B1v)

La acotación se localiza después del baile inicial de las ninfas y de una serie de cuatro réplicas en las que deducimos, ya que sabemos que fueron doce las participantes, intervendrían en grupos de tres, y nos aporta además la identidad de quien cantaba las réplicas de la Música, la madre Juana Teresa de San Antonio. Del mismo modo, aparece inmediatamente antes de la salida de Tetis una de las protagonistas de lo que apunta ser la Loa, para ambientar su réplica en el marco del elogio a la condesa de Paredes:
A la estrella de Manrique,
glorioso timbre de Lara,
cuando su piélago surca
celebran todas las aguas.
llustrada de su vista.
es la marina campaña,
tranquilo golfo de nieve,
lucido campo de plata.
Al llegar al Occidente,
Tetis para celebrarla
a sus ninfas y sirenas
así plausible llamaba. (Festín, B1v)

La tipología genérica de la loa recurre a dos personajes alegóri$\cos$, Tetis y Flora, que protagonizan un debate en el que exponen sus méritos simbólicos para patrocinar la celebración de la destinataria de la pieza. La discusión se organiza en réplicas simétricas y con razones alegóricas complementarias, puesto que sus respectivas virtudes son equiparables desde el ámbito marítimo propio de Tetis y el terrestre de Flora, como ya marcaran las coplas del baile inicial entre "arroyos" y "campos». La discusión pretende crear una especie de realidad envolvente en la que se impliquen unas coordenadas espaciales que abarquen el espacio físico de tierra y agua, así como las temporales que se derivan de esta simultaneización del conflicto dramático, que logra implicar en la puesta en escena de elogio a la virreina a dos deidades mitológicas. Además, la convención escénica marcada por las coplas del baile de apertura, que convertía a las «niñas del Convento» en ninfas de prados y arroyos, refuerza la ilusión dramática del elogio, pues le otorga un mayor grado de verosimilitud al transformar la clausura del convento en el decorado mitológico del debate entre Tetis y Flora. La primera aparece con un

ondeado vestido [que] bien daba a entender las ondas que como tal pedía, pues siendo esposa del cristalino [falta una línea], siendo esto el que ciñe con sus cristales todo el ámbito de la tierra. [...] Con razón hacía lucida metáfora de las aguas en su vestido, sacando sobre azul ondas de plata y con razón también celebra a la que habiendo navegado en sus aguas, por ser de mejor Océano, esclarecida esposa fue venerada Tetis, cuya beldad en las aguas: Envidia de las ninfas y cuidado / de cuantas honra el mar deidades era. (Festín, B1v-B2r)

La aparición de Flora es por el otro lado del escenario. La simetría y la complementariedad entre ambas se refuerza, como en el caso anterior de Tetis, con una alusión panegírica a la virreina como referente real del personaje alegórico que representa:

[...] cuando por el otro lado fue saliendo Flora con una artificiosa guirnalda de cuantas Mayo esparce a los jardines deliciosas fores, y en la mano un ramillete de las mismas, tan propias que parece pudieran prestar lucimientos al más florido Abril; a éste dibujaba en sí Flora, que para acreditarse viviente prado, salió vestida de tela verde, y admirada a la beldad de la nueva Flora, que en sus'amenos pensiles era dulce atractivo de su afecto, acordó de aplaudirla con sus flores, pues si aquestas (como dijo Pierio) son seguro prenuncio de la felicidad [...], no es mucho que a quien tantas felicidades nos asegura, pretendiese celebrar con ellas la deidad de las flores que en tan festivo aplauso dijo así: (Festín, B3r)

Éstas, tras invocar a sus respectivos coros de ninfas y lograr alcanzar el clímax espectacular de la puesta en escena, siguen en una discusión aparentemente irresoluble, cuyo desenlace vendrá de la mano de un juez mediador en la disputa: la Fama, el único personaje alegórico con entidad simbólica suficiente como para ejercer dicha posición preponderante entre ambas. La acotación es explícita cuando lo visual y lo auditivo confluyen como metáforas escénicas de su preponderancia: 
Al son de aquestos dulces músicos acentos, fue saliendo por en medio de las dos la Fama, que por haber llegado en la pompa de su gala de la curiosidad a los extremos, para salir buscó un medio saliendo a ser dulce rémora de cuantos ojos linces de su gala o [hélices] de su lucimiento, se desvelaban en ver lo lucido del laurel que victoriosa ceñía [...] para repetir las glorias de la Exma. Princesa a quien aclamaba. Sacó triunfante clarín, con que llevándose la palma en la bizarría, consiguió el llevarse la aclamación de todas [...]. De más lucida en su gala, la Fama es la que merece este lauro de celebrar a su Exa. Sea pues la Fama noble desempeño de todas en rendirle único aplauso. (Festín, B4r-B4v)

Tras un largo parlamento en el que consigue integrar los méritos simbólicos de las dos protagonistas del debate en la notoriedad que representa la condesa de Paredes, la Fama cierra la pieza al son de una serie de cuatro coplas que canta la Música, repitiéndose la primera al final como estribillo:

Suenen los clarines,
retumben las cajas
porque sus laureles
publique la Fama.
Triunfante ha salido
hoy de la campaña
y en una victoria
consigue dos palmas,
y pues ha vencido
su diestra gallarda
de Tetis la gloria
de Flora la gala. (Festín, C1v)

La Fama es el personaje que permite trascender la metáfora mitológica del elogio que personifican Tetis y Flora y conseguir así la "victoria». Desde luego que en este debate alegórico, el personaje de Tetis alude no sólo al viaje que la virreina debe realizar por mar hasta llegar a México, sino también a la fama de su belleza que trasciende los mares, del mismo modo que su oponente Flora logra sugerir la excelencia de la virreina entre todas las flores / damas de la corte novohispana, como ya se apuntaba en las acotaciones que describían su vestuario.

La clausura del convento es, como hemos podido comprobar en este Festín-Loa del convento de Santa Clara a la condesa de Pare- des, el espacio en el que la figura simbólica de la virreina logra un protagonismo absoluto mediante la alegoría mitológica en la que se ambienta el debate entre Tetis y Flora. El tono y las estrategias laudatorias se repiten en el caso de las celebraciones públicas en torno a virrey, aunque para dichas ocasiones, como veíamos en la tradición marcada por el protocolo, el protagonismo absoluto es para el nuevo gobernante. En el caso novohispano, los modelos iconográficos para dicho elogio surgen casi exclusivamente de las entradas públicas de los virreyes. Un claro ejemplo es el recibimiento que la ciudad de Puebla dedicó el 16 de octubre de 1688 a la entrada del conde de Galve $^{33}$. La alegoría de las arquitecturas efímeras concertadas parte de la inicial metáfora que equipara al conde de Galve como un "sol en león"14. El arco, al cuidado del regidor D. Nicolás de Victoria Salazar, reproduce en el primer tablero los orígenes de la metáfora y

${ }^{13}$ La referencia completa aparece en la bibliografía final y en adelante citamos con el nombre de Sol esclarecido e indicando entre paréntesis el número de folio, habiendo modernizado la ortografía y la sintaxis.

${ }^{14}$ EI autor especifica en la dedicatoria de los preliminares los singulares motivos que lo conducen a esta metáfora compuesta, surgida de las equivalencias entre planetas y signos zodiacales:

En otras ocasiones podrá ser el Sol, como especie tan común, lo primero que se ofrece a la idea y se viene a la pluma para elogio de Príncipes y Monarcas. Mas exaltado hoy en el León, como blasón antiguo de la Casa de V. Ex., así en las armas de los excelsos Gómez de Sylva, como en los dos cuarteles de los ilustres Condes de Galve, hace que un planeta acostumbrado a entrarse cada día en todas las casas del mundo sublunar, se halle, y bien, para aplauso de V. Ex. como en su gozo y propia casa en los timbres que la ennoblecen; y éste es el privilegio del Ieón celeste, que cuando los otros planetas, fuera de la luna, tienen a lo menos dos diversos domicilios, como Saturno, que tiene casa en Capricornio y Acuario; Júpiter en Sagitario y Piscis, y así los demás, el León es única, sola y particular casa del Sol. La junta, pues de uno y otro, del Sol en león, es la que yo pretendo sea algún diseño de las grandezas de tanto príncipe para que los que de por sí fueran más que suficiente emblema para alabanzas de muchos otros, juntos y unidos digan algo de lo que en su persona y excelentísima casa venera con admiración todo el Orbe.

Otras veces suele adornarse la real Portada, no sin plausible gallardía de los ingenios o con fábulas de dioses mentidos, o con historias de héroes que dama ron semidioses; no repruebo, Señor, lo que con razón ba sido loable, y bien visto de los doctos, mas con deseo de significar mis estimaciones en la alegría festiva de $\mathrm{V}$. Ex., digo que aun me parece poca toda la luz del sol para sombra de sus proezas, y menos empresa coronado rey de los cuadrúpedos para desempeño de lo que debe decirse y sin lisonja alguna ponderarse. 
en el segundo un repaso a la genealogía del nuevo virrey. El tercero se dedica a la entrada en la ciudad y, tras la descripción del carro del Sol, pasa a detallar el de la Aurora, que simboliza a la virreina:

Al otro lado se veía el carro de la Aurora tirado de dos hermosísimos caballos de color de rosa, jaeces de lo mismo, y del mismo color era todo el Carro y vestido de la Aurora, Plena rosarum, de donde al descuido se desgajaban bellísimas rosas de Castilla, que hacían del pavimento un paraíso, y de lo alto estaba como péndula hacia la cabeza de la prodigiosa Señora una guirnalda también de rosas con el mote: Aurora in roseis, de Virgilio, y otro que era el resto del hemistiquio de Marcial, que decía Redde diem. Desde luego, se dejaba entender que era la deidad que ocupaba aquel carro la dignísima Consorte de tal Sol: la Exma. Señora Doña ELVIRA DE TOLEDO Y OSSORIO, en quien si discurrieran una por una las razones que la aventajan Aurora se formara otro Arco de más extensos tamaños [...]. Si como Aurea hora, que eso quiere decir Aurora, es Su Ex. la hora de Oro feliz, que nos trae el día en el sol que veneramos [...]. Daba el cuadro qué ver y en qué entender aun a los demás tableros, que estuvieron a riesgo de quedarse a oscuras a vista de tantas luces y tantos soles de este que representó a la entrada [...]. (Sol esclarecido, 6r-6v)

La hipérbole mitológica permite que el referente real de la condesa de Galve supere al de la Aurora, al tiempo que la ecuación simbólica entre rosas y luces se refuerza icónicamente con el rosa del que se pinta su carró. Resulta interesante que ante tantas hipérboles y reiteraciones, la descripción del carro precise explícitamente que «se dejaba entender que era la deidad que ocupaba aquel carro la dignísima Consorte de tal Sol». Es precisamente este último emblema el que nos permite, para concluir, retomar la iconología de una de las metáforas características para las reinas de los Austrias: la de la Aurora, construida a partir de luces y rosas.

Esta coincidencia nos permite comprobar que, en lo esencial, se repiten las estrategias áulicas para el elogio entre reinas y virreinas y que la práctica de los fastos cortesanos resulta el marco en el que se

[...] Pero yo me vuelvo a mi sol y león, que como siento generosos bochornos y hidalgos deseos de servir a V. Excelencia, me parece que desahogará mi afecto respirando (sólo por indicio) un Sol ardido y un León abrasado, que sea (signo no más) de las veras y voluntad con que desea servir y obedecer a V. Excelencia con singulares demostraciones de su afecto y lealtad. (sf) fija el modelo arquetípico de consorte femenina. En determinadas y puntuales ocasiones, se dan prácticas festivas en las que es posible un elogio unilateral a la figura femenina que, para el caso virreinal, se localizan puntualmente en los conventos de clausura.

Con la subida al trono de los Borbones, el perfil de los virreyes, y por tanto también el de las virreinas, cambió por completo; puesto que desparecerían paulatinamente las connotaciones señoriales de cargo. A partir de 1710 la nobleza ya no sería más el principal mérito para obtener el gobierno, sino que los «administradores, militares recaudadores de impuestos de origen modesto, surgidos de la nueva casta burocrática creada en España por los reformadores franceses en los primeros años de Felipe V" pasaron a ejercer el cargo ${ }^{15}$. Después de los duques de Alburquerque en 1710, no volvería a aparecer un virrey casado hasta 1745 , lo que implicaba que la corte como espacio de refinamiento social pasaría a extinguirse irremediablemente y que la oligarquía novohispana habría de buscar nuevos espacios para la ostentación y la defensa de sus privilegios, amenazada con la modernización de los nuevos planes borbónicos. Desaparecía así el fasto espectacular en el que Auroras y ninfas podían convertirse en metáforas para la retórica áulica del encomio femenino, por lo que la transformación simbólica daría paso a uña nueva realidad social.

\section{BIBLIOGRAFÍA}

ANDrade, V. P., Ensayo bibliográfico mexicano del siglo xVIl, México, Imprenta del Museo Nacional, 1899.

Barrera, J., FESTÍN / PLAVSIBLE, / CONQVE EL RELIGIOSSIMO / Convento de Santa Clara de esta Ciudad, / celebró en su felize entrada / A LA EX.MA SEÑORA / D. MARIA LVISA / GONZAGA, MANRIQVE / LARA, CONDESA DE PAREDES, / MARQVESA DE LA LAGVNA, / Y VI-REYNA DE ESTA / NVEVA-ESPANAA, \&C. / A cuyas plantas lo Dedica obsequioso, $y$ ofrece / rendido / Br. D. Joseph de la Barrera Barahona. / CON LICENCIA: / En Mexico, por Juan de Ribera, Impresor, y Mercader de Libros / en el Empedredadillo. Año de 1681, ejemplar depositado en la Biblioteca Cervantina del Tecnológico de Monterrey: Colección Méndez Plancarte, M 861.1 B 27281681.

Beristain de Souza, J. M., Biblioteca hispanoamericana septentrional, México, Calle de Santo Domingo y esquina de Tacuba, 1816.

\footnotetext{
${ }^{15}$ Escamilla González, 2005, p. 395.
} 
P. de Valtierra, M., SOL EN LEON, / ASCENDENCIA ESCLARECIDA, / EXALTACION GOZOSA. / DISCURRIDA EN LAS EMPRESAS, / y Symbolos Politicos de el Arco Triumphal, / que erigió la Ciudad de la Puebla de los Ange- / les, para el diez y seis de Octubre de ochen- / ta y ocho destinado a laSolemne, y / feliz entrada de / EL EXCELENTISSIMO Y ocho destinado a lasolemne, Don Gaspar da Cerda, Sandoval, Sylva, y / Mendoza, Conde de Galve, Gentil-hombre de / la Camara de Su Magestad, Señor de las Villas I de Sacedon, $y$ Tortola, Caballero del Orden de / Alcantara, $y$ Comendador de Zalamea, $\gamma$ Cecla- / vin, Alcayde perpetuo de los Reales Alcaza- / res Puertas, $y$ Puentes de la Imperial Toledo, / y del Castillo, y Torres de la Ciudad de Leon, I VIRREY, GOVERNADOR, YCA- / pitan General de esta Nueva-españa, $\gamma$ Presi- / dente de la Real Audiencia Ec. I A QVIEN VNA, Y OTRA VEZ LO DE- / dica, y Consagra. / Con Licencia, en la Puebla de los Angeles, en la Imprenta Nueva / Plantiniana de Diego Fernandez de Leon. / POR EL P. MANUEL DE VALTIERRA de la Compañia de JESVS, ejemplar depositado en la Latin American Benson Collection de la Universidad de Austin en Texas: GZ 868.72 P75

Escamilla GonzÁlez, I., "La corte de los virreyes", en La ciudad barroca, coord. Antonio Rubial García, México, Colegio de México-FCE, 2005, col. Historia de la vida cotidiana en México, vol. II, pp. 371-406.

García Pares, D., Diario particular del camino que sigue un virrey en México, Ed. Facsimilar, Oviedo, Centro de Estudios Históricos de Obras Públicas y Urbanismo (CEHOPU) y Ministerio de Obras Públicas, Transportes y Medio Ambiente, 1994.

López Torrjos, R., La mitología española en la pintura del Siglo de Oro, Madrid, Cátedra, 1985.

Mrinina, J. T., La imprenta en México (1539-1821), Santiago de Chile, en casa del autor, 1907, vol. II.

Mínguez, V., «La metáfora lunar: la imagen de la reina en la emblemática española", Millars: Espai i Història, XVI, 1993, pp. 29-46.

Ramos, M., «Los virreyes de la Casa de los Austrias», en El otro yo del virrey. Virreyes de la Nueva España 1535-1821. Catálogo de la exposición en el Museo Nacional de Historia, México, Porrúa, 1996, pp. 29-41.

RipA, C., Iconología, Madrid, Akal, 1996.

Romero de Terreros, M., Bocetos de la vida social en la Nueva España, México, Porrúa, 1944.

Ruzz Lagos, M., «Algunas relaciones pictóricas y literarias en el teatro alegórico de Calderón", Cuadernos de Arte y Literatura, Universidad de Granada, 1, 1967, pp. 21-71. 